\title{
Generation of layering in the upper arctic troposphere away from the jet stream
}

\author{
A. Karpetchko ${ }^{1,2}$, E. Kyro ${ }^{1}$, and P. von der Gathen ${ }^{3}$ \\ ${ }^{1}$ Finnish Meteorological Institute, Arctic Research Centre, Tähteläntie 62, FIN-99600 Sodankylä, Finland \\ ${ }^{2}$ on leave from the Polar Geophysical Institute, Fersman Str.14, 184209, Apatity, Russia \\ ${ }^{3}$ Alfred Wegener Institute, D-14473 Potsdam, Germany
}

Received: 23 August 2002 - Revised: 24 December 2002 - Accepted: 9 February 2003

\begin{abstract}
Ozone sounding databases for two stations, Sodankylä $\left(67^{\circ} \mathrm{N}, 27^{\circ} \mathrm{E}\right)$ and $\mathrm{Ny}$-Ålesund $\left(79^{\circ} \mathrm{N}, 12^{\circ} \mathrm{E}\right)$ were used in order to investigate the generation of layering in the upper and middle troposphere of the Arctic. We concentrated on dry, ozone-rich and stable layers observed below the thermal tropopause under light wind conditions. This condition ensures that the observed layer is not a tropopause fold, a well-known phenomenon that develops within frontal zones near the jet stream. Selection criteria for ozone, humidity and stability anomalies of the tropopause fold detection algorithm were used here to pick out for detailed studies the most pronounced examples of laminae. For all these cases the meteorological situations were investigated in order to establish the origin of the observed layers. We found that layers could be classified into two groups. Laminae of the first group were observed equatorward of the jet stream and those of a second group were observed poleward of the jet. The meteorological situation for the first group resembles that for equatorward stratospheric streamer propagation. It was found that this group accounts for only a small fraction of the layers observed at Sodankylä and for none of those observed at Ny-Ålesund during the period investigated. A large case-to-case variability in the synoptic situation was observed for the second group of laminae, which were detected northward of the jet stream. Nevertheless, in about half of the cases, streamers of tropospheric air were found in the vicinity of the stations on the isentropic surfaces just above the detected stratospheric layers. Back trajectory analyses showed that these layers originated in the vicinity of the polar jet stream. We suppose that laminae-like structures in the troposphere were caused, in both groups, by equatorward (poleward) advection of the stratospheric (tropospheric) air, together with differential vertical shear. Forward-trajectory calculations suggest that, subsequently, a part of the stratospheric layers can mix irreversibly into the troposphere.
\end{abstract}

Key words. Atmospheric composition and structure (pressure, density, and temperature; troposphere-composition and chemistry)

Correspondence to: A. Karpetchko

(alex.karpetchko@fmi.fi)

\section{Introduction}

It is widely recognised that stratosphere-troposphere exchange (STE) in the extratropics occurs mainly through mesoscale, temporarily isolated processes, such as tropopause fold development or convective erosion of the tropopause within upper-level cutoff lows (Danielsen and Monhen, 1977; Shapiro, 1980; Price and Vaughan, 1992; Ancellet et al., 1994). Since the upper troposphere and the lower stratosphere differ significantly in their chemical composition and dynamical properties, STE processes can considerably modify both regions. For example, the amounts of upper tropospheric ozone, as well as lower stratospheric water vapour, strongly depend on the intensity and frequency of such events. Mixing across the interface of these regions can also have other important chemical consequences, e.g. the enhanced production of the $\mathrm{OH}$ radical (Esler et al., 2001), which is a key component of tropospheric photochemistry. Moreover, STE leads to the formation of mesoscale flow features at tropopause levels, such as streamers, that have implications for weather system development (Appenzeller et al., 1996).

A lot of attention has been paid in recent years to improving our knowledge of the mechanisms responsible for STE, and now many aspects of the process are well understood. The exchange of mass between the stratosphere and the troposphere on a climatological time scale can be calculated from the meridional circulation of the stratosphere and mesosphere (Holton et al., 1995), but the details of the exchange processes on the synoptic and sub-synoptic time scales, especially in the tropopause region, have yet to be understood. Indeed, there are still large uncertainties in the quantitative description of STE, mainly arising from a shortage of information about the mechanisms that lead to irreversible mixing of the material.

The extreme dryness, significantly larger ozone concentration and higher potential vorticity (PV) values of stratospheric air provide the elements for distinguishing it from tropospheric air, using the vertical profiles of one or all of these properties. Potential vorticity is a derived dynamical quantity which does not change in adiabatic motions and is 
defined as: $\mathrm{PV}=-g \cdot(\zeta+f) \cdot \partial \theta / \partial p$. Here, $g$ is gravity acceleration, $p$ is pressure, $\theta$ is potential temperature, $\zeta$ and $f$ are the isentropic relative and planetary vorticities, respectively. A PV value can be used as a definition of tropopause, and usually the threshold value is set near $2 \mathrm{PVU}$ (1 PVU = $10^{-6} \mathrm{~km}^{2} \mathrm{~kg}^{-1} \mathrm{~s}^{-1}$ ).

The existence of layers of high ozone concentration in the upper troposphere, as well as layers of low ozone concentration in the lower stratosphere, has long been recognised (Dobson, 1973). Layering of stratospheric air within the middle and upper troposphere is usually observed in the vicinity of a jet stream (Danielsen et al., 1970; Shapiro, 1980). This phenomenon is known as a tropopause fold, and results from the ageostrophic vertical circulation across an upper-level front (Hoskins and Bretherton, 1972). Threedimensional, as well as continuous pictures of tropopause fold development have been obtained using airborne in-situ gas measurements and both airborne and ground-based lidar observations (Danielsen et al., 1987; Browell et al., 1987; Ancellet et al., 1991). Only a few years ago the statistical properties of tropopause fold occurrence were obtained from regular balloon-borne observations (Van Haver et al., 1996; Beekmann et al., 1997). It should be mentioned here that a tropopause fold on its own does not lead to irreversible mass transfer between stratosphere and troposphere, and the main part of the stratospheric air that descends during upper-level frontogenesis then returns to the stratosphere as a result of the frontolitic vertical circulation. The irreversible stratosphereto-troposphere mixing of part of the intruded tongue is due to the presence of other processes that usually accompany the tropopause fold. These processes include instabilities (e.g. clear air turbulence, streamer fragmentation) and diabatical processes (moist convection, radiation) (Langford and Reid, 1998; Shapiro, 1980; Cho et al., 1999; Appenzeller and Davies, 1992).

Since the early STE studies the investigation of layering in the vicinity of tropopause was restricted mainly to the tropopause fold events. However, there are evidences that not all layers near the tropopause could be referred to as a tropopause fold (Van Haver et al., 1996; Zachariasse et al., 2000; Bithell et al., 2000). Zachariasse et al. (2000) suggested distinguishing between tropopause folds and filaments because "in folding the vertical movement is important, whereas for the filaments horizontal stretching is more important". We adopt this definition here but it should be also taken into account that the horizontal transport could follow initial descent of the air in the fold. It is important to repeat that tropopause fold is a reversible process (Shapiro, 1980), whereas subsequent quasi-horizontal transport and strong deformation of the global-scale tracer fields start during the nonlinear phase of the wave development as a result of wave breaking that is, in turn, an irreversible process (Thorncroft et al., 1993; Peters and Waugh, 1996). The term Rossby-wave breaking was probably first used by McIntyre and Palmer (1983) to describe the strong deformation of the initially undular passive tracer (e.g. potential vorticity) contours on an isentropic surface. Peters and Waugh (1996) suggested a distinction between poleward and equatorward Rossby wave breaking, depending on the direction in which the material has been transported. The deformation can take the form of streamers frequently observed in the tropopause region in water vapour images and isentropic PV charts (Appenzeller and Davies, 1992; Appenzeller et al., 1996). The streamers stem from the initial tropopause fold, propagate through the jet stream and create strong horizontal gradients of tracers away from the jet stream. The resulting gradients combined with vertical shear create the potential for folding of tracer surfaces and subsequent mixing (Appenzeller and Holton, 1996). This process could be of importance in the generation of layering near the tropopause region.

Transport of subtropical tropospheric air into the lower stratosphere by the breaking of Rossby waves near the subtropical jet was recently studied by Bradshaw et al. (2002). Layering in the troposphere away from the jet stream has been studied less. This is especially true for the Arctic, since only a few observational studies connected to STE have been performed (e.g. Shapiro et al., 1986). The main goal of this investigation is to establish the connection between the layering of stratospheric air in the upper and middle troposphere away from the jet stream and the dynamical processes involved. In this paper, both case studies and a statistical approach are presented to describe layering generation in the Arctic troposphere.

\section{Data and method}

Ozone sounding data sets from two Arctic stations were used in this investigation. Regular balloon-borne measurements of ozone have been performed at Sodankylä, $\left(67.4^{\circ} \mathrm{N}, 26.7^{\circ} \mathrm{E}\right)$ since 1988. Up to April 2000 more than 800 profiles had been recorded. The frequency of the soundings varies between one per week during the summer and autumn, and one per day during intensive winter-spring campaigns. There were a few periods with less frequent soundings, but these were mainly at the beginning of the observation series. The ozonesonde data set for $\mathrm{Ny}-\AA$ Alesund $\left(78.9^{\circ} \mathrm{N}, 12.0^{\circ} \mathrm{E}\right)$ was available for the period from November 1991 until April 2000 and consists of more than 900 profiles. In addition to ozone measurements, the data sets also include pressure, temperature, humidity, and wind data. Additional data for case study analysis were available from the routine daily meteorological radiosonde measurements performed at Sodankylä.

Fields of meteorological variables, such as geopotential heights, temperature and the $u$ - and $v$-components of the wind have been retrieved from the European Centre for Medium Range Weather Forecasts (ECMWF) T213-analyses that have a horizontal resolution of about $0.6^{\circ}$. In order to more realistically reflect the density of the observational network, a regular $1^{\circ}$ resolution in both latitude and longitude was chosen. We used data bases with both pressure and model hybrid-sigma vertical coordinates. Linear interpolation between model levels was used to obtain meteorological 
a

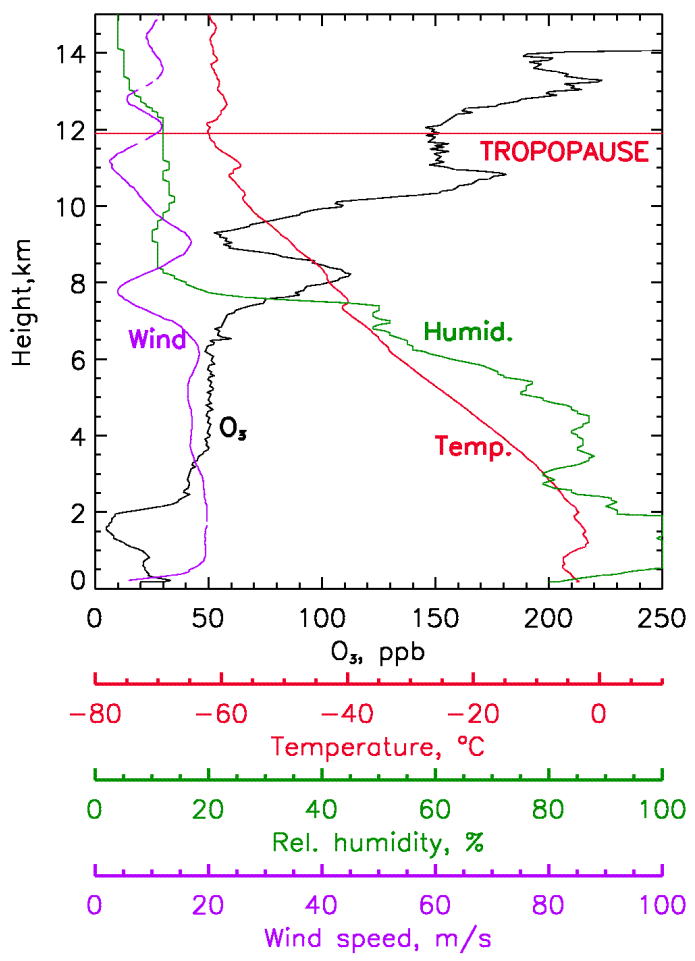

b



Fig. 1. (a) Sodankylä profiles of ozone, relative humidity, temperature and wind speed at 12:00 UTC on 10 November 1993 and (b) $300 \mathrm{hPa}$ geopotential height (decameters) at 12:00 UTC on 10 November 1993. Superimposed are wind vectors. Sodankylä is marked with a diamond.

fields on isentropic levels. Isentropic PV-calculations were performed using the method described in Rummukainen et al. (1994).

Backward and forward isentropic trajectories of air particles were constructed using HYSPLIT 4 (HYbrid SingleParticle Lagrangian Integrated Trajectory Model, 1997; web address: http://www.arl.noaa.gov/ready/hysplit4.html, NOAA Air Resources Laboratory, Silver Spring, MD). The details of the model are described in Draxler (1996). The wind fields that drive the trajectories are given on the polar stereographic grid with horizontal resolution of about $190 \mathrm{~km}$ at standard pressure levels. These fields are extracted from original meteorological analysis, produced by the National Centers for Environmental Prediction (NCEP) operational model with a resolution of $1^{\circ}$ in both latitude and longitude. Isentropic trajectories have the advantage that they depend only on the horizontal components of the assimilated winds, while 3-D trajectories require a less accurate vertical velocity field. The accuracy of isentropic trajectories depends on the intensity of the diabatic processes, which in the isentropic approach are neglected. For the dry tropopause region such an assumption is valid over the period of a few days used in this analysis. Other sources of error in trajectory calculations arise from interpolation of sparse meteorological data, observational errors and sub-grid-scale phenomenon.

To pick out layering events from the complete ozonesonde data sets we used the automatic algorithm developed by Van
Haver et al. (1996) for tropopause fold detection. This algorithm allows for the detection of a stratospheric intrusion from profiles of ozone, temperature, pressure, humidity and wind. The threshold values used in the algorithm were as follows: (1) the ozone mixing ratio should be enhanced by at least $25 \%$ compared to the climatological mean and compared to adjacent minima in the ozone profile, (2) the static stability should be larger than $11.5 \mathrm{~K}$ per $100 \mathrm{hPa}$, and (3) the relative humidity should be below $25 \%$. It is worth mentioning here that, as found by Van Haven et al. (1996), the statistics of stratospheric layers obtained with an automatic algorithm depend only to a small extent on the humidity criterion. They concluded that a humidity criterion is to a large extent redundant. We found that skipping the criterion changes the results by less than $10 \%$ and so the dry bias of the radiosonde humidity sensor (e.g. Miloshevich et. al., 2001) would not influence the results significantly.

In order to exclude the tropopause fold events, all cases observed in the jet stream were rejected. Thus, we only accepted events when the following conditions were fulfilled: (4) maximum wind speed in the troposphere should be lower than $20 \mathrm{~m} / \mathrm{s}$ or (5) the vertical wind shear throughout the free troposphere should be less than $5 \mathrm{~ms}^{-1}$ per km. Through the thermal wind equation, condition (5) implies the absence of well-developed frontal zones in the vicinity of the station. It turned out that in only a few cases did the wind speed exceed the threshold value for a jet stream in combination with 
a weak wind shear. Including these additional cases does not impact the general conclusions.

\section{Generation of layering resulting from an equator- ward rossby wave breaking event}

We start with a case observed on 10 November 1993 at Sodankylä. Balloon-borne observations made at 12:00 UTC on that day are presented in Fig. 1a. An ozone maximum of $115 \mathrm{ppb}$ is located between 7 and $9 \mathrm{~km}$, corresponding to a potential temperature range of $305-320 \mathrm{~K}$. A temperature inversion is located at the bottom of the layer and the relative humidity decreases within the inversion from $50 \%$ to $10 \%$. The second layer of enhanced ozone values centred on the $329 \mathrm{~K}$ isentropic level is located just below the thermal tropopause, with an ozone maximum of $185 \mathrm{ppb}$ at $10.5 \mathrm{~km}$. The maximum wind speed in the troposphere does not exceed $17 \mathrm{~m} / \mathrm{s}$, which is lower than values usually observed in a jet stream. Nevertheless, vertical wind shear is observed above $6.5 \mathrm{~km}$. First, the wind speed decreased from $17 \mathrm{~m} / \mathrm{s}$ to lower than $5 \mathrm{~m} / \mathrm{s}$ at about $8 \mathrm{~km}$ and then increased again to $16 \mathrm{~m} / \mathrm{s}$ at $9 \mathrm{~km}$. Oscillations in the wind speed follow those in the ozone, but with the opposite sign. The second minimum in wind speed also coincides with the ozone maximum. The wind direction changed from $230-250^{\circ}$ below the first ozone maximum to $120^{\circ}$ in its upper part and then to $310-330^{\circ}$ at $12 \mathrm{~km}$.

Geopotential heights and wind vectors on the $300 \mathrm{hPa}$ pressure surface for 10 November are depicted in Fig. 1b. The jet stream is seen to propagate far northwards, with the station positioned on its equatorward side. The amplification of the ridge, which followed the poleward excursion of the jet stream, resulted in the development of a cutoff anticyclone centred over Northern Scandinavia. Another significant synoptic-scale feature on the map is the upstream-tilted trough southeast of Sodankylä, stretching from the Taimyr Peninsula towards the Ukraine.

Successive $310 \mathrm{~K}$ isentropic PV charts, as presented in Fig. 2, provide a useful tool for investigating the development of synoptic systems in a dynamical context. The $310 \mathrm{~K}$ isentropic level corresponds to the lower ozone layer just below $8 \mathrm{~km}$. In this investigation we have adopted the 1.6 PVU contour as a threshold value between the troposphere and the stratosphere (Danielsen and Hipskind, 1980). On 7 November (Fig. 2a), the deep equatorward excursion of the trough above the North Atlantic has led to the formation of a stratospheric streamer, which can be seen as a high PV band just west of Ireland. Stratospheric air descended down to $600 \mathrm{hPa}$ in a tropopause fold on the western flank of the trough. This streamer was advected with the large-scale flow northeastward during the next 3 days (Fig. 2b-d). By 12:00 UTC on 10 November the streamer had developed into a thin meandering streamer, the tip of which reached the station (Fig. 2e). Amplification of the wave perturbation on the band eventually led to the fragmentation of the streamer and formation of the vortex centred at $60^{\circ} \mathrm{N}, 50^{\circ} \mathrm{E}$ (Fig. 2f). The growth of wave perturbation can be explained by the dynamical instability (Appenzeller et al., 1996). It was shown theoretically that a two-dimensional streamer is subject to a baroclinically modified form of classical barotropic instability (e.g. Schär and Davies, 1990).

The evolution of the streamer presented in Fig. 2 shows all the features of the life-cycle of the LC1 type of equatorward Rossby wave breaking (Thorncroft et al., 1993; Appenzeller et al., 1996): initialisation, upstream tilting and equatorward propagation during the maturing stage, wave development on the band and fragmentation into a train of the vortices. We believe that, as the streamer passed over the station, it was observed in the sounding as a dry, ozone-rich and stable layer centred at a height of about $8 \mathrm{~km}$, that is about $310 \mathrm{~K}$. Trajectory analysis (not shown) confirms that air at about $310 \mathrm{~K}$ originated from the tropopause region near the streamer depicted in Fig. 2a. It should be mentioned, however, that the synoptic-scale poleward advection of tropospheric air that occurred simultaneously with the stratospheric streamer propagation, rather resembles poleward Rossby wave breaking. Indeed, development of the cutoff anticyclone, usually referred to as a "blocking anticyclone", is a typical feature of P2-type Rossby wave breaking (Peters and Waugh, 1996).

The laminae structure in the upper troposphere and lower stratosphere is evident from the sonde profile where the static stability correlates positively with ozone. However, vertical profile of PV from ECMWF analysis revealed only a monotonic increase, with stratospheric values starting from $310 \mathrm{~K}$. ECMWF wind agrees quite well with the radiosonde observation up to about $8 \mathrm{~km}$ with maximum absolute deviation less than $4 \mathrm{~m} / \mathrm{s}$. However, the analysis fails to see the wind maximum at $9 \mathrm{~km}$. Since PV fields are derived from the wind fields we conclude that ECMWF resolution is too coarse to resolve fine laminae present in the radiosonde profile higher than $320 \mathrm{~K}$. However, examination of PV maps reveals streamers of low PV air above $320 \mathrm{~K}$ in the vicinity although not exactly above the station. We refer to this case as an example of layering resulting from equatorward breaking, because observation of the layering was made southward of the jet stream in the anticyclonic large-scale flow shear. It is a stratospheric streamer at $310 \mathrm{~K}$ that has propagated through the jet stream and intruded into the upper troposphere. Horizontal ozone gradients caused by the streamer, together with differential vertical shear resulted in folding of ozone surfaces that led to a laminae-like structure in the upper troposphere and lower stratosphere.

Such a far northward penetration of the jet stream is not part of the day-to-day weather system development in high latitudes; Sodankylä is usually located north of the polar front. Therefore, it would be expected that poleward Rossby wave breaking plays a more important role in layering generation in the Arctic. We now proceed with a case study of layering observed on the northward side of the jet stream. 

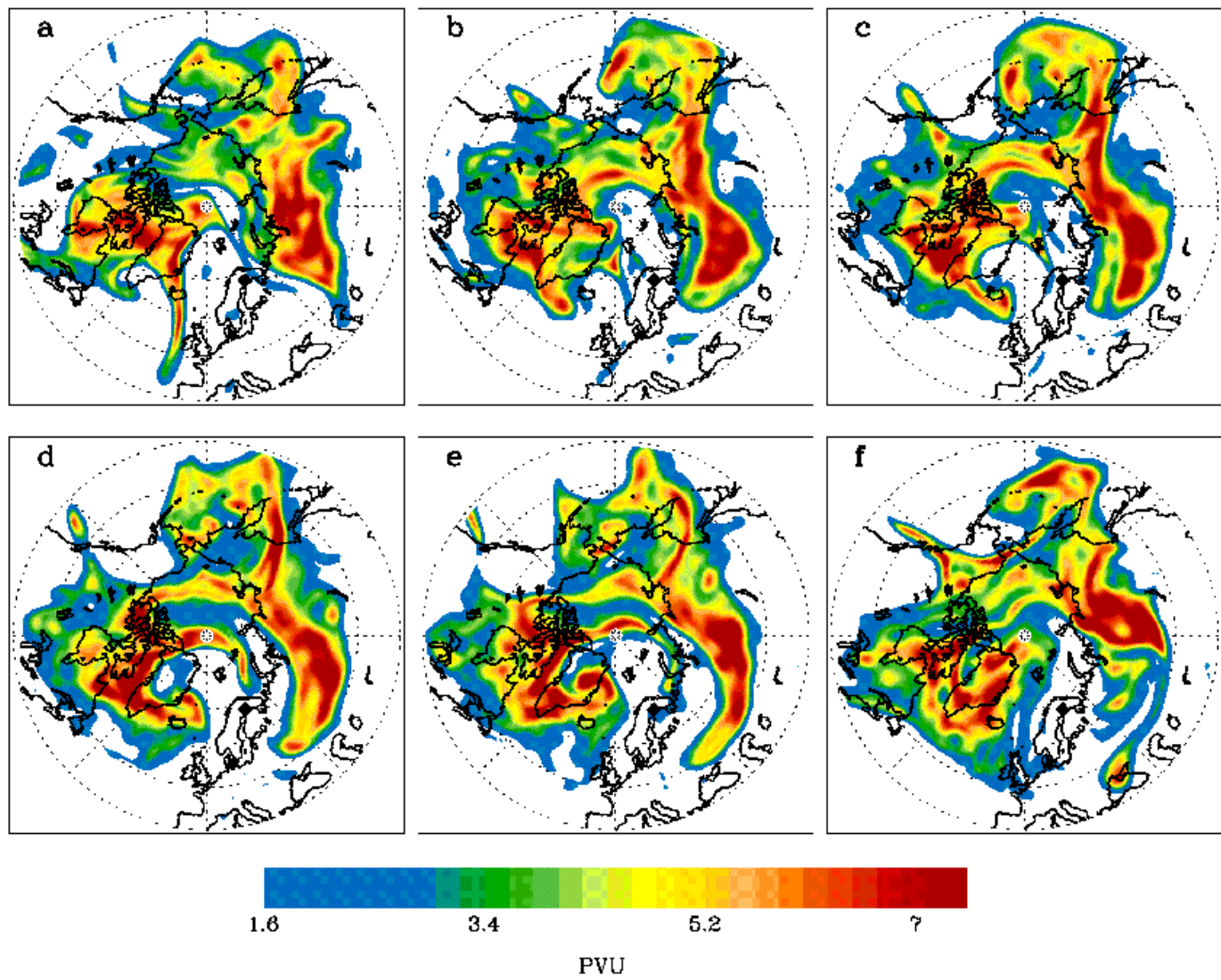

Fig. 2. PV charts calculated for the $310 \mathrm{~K}$ isentropic surface at (a) 12:00 UTC on 7 November; (b) 00:00 UTC (c) 12:00 UTC on 9 November (d) 00:00 UTC (e) 12:00 UTC on 10 November; (f) 12:00 UTC on 11 November. Sodankylä is marked with a diamond. Only PV>1.6 PVU is coloured.

\section{Generation of layering resulted from a poleward rossby wave breaking event}

The event presented here was observed on two successive ozone soundings on 16-17 February 2000 at Sodankylä. The sounding performed at 12:00 UTC on 16 February revealed a dry, stable and ozone-rich layer between $5.5-6.6 \mathrm{~km}$ with maximum ozone of about $100 \mathrm{ppb}$ at $6.2 \mathrm{~km}$ (Fig. 3a). In this layer the potential temperature increased rapidly from $289 \mathrm{~K}$ at $5.5 \mathrm{~km}$ to about $300 \mathrm{~K}$ at $6.6 \mathrm{~km}$, with maximum ozone occurring at the $297 \mathrm{~K}$ level. The Brunt-Väisälä frequency in this layer $\left(\mathrm{N} \approx 1.8 \cdot 10^{-2} \mathrm{~s}^{-1}\right)$ was close to stratospheric values. A temperature inversion was located at the bottom of the layer and relative humidity dropped within the inversion from $20 \%$ to less than $5 \%$. This layer appeared on the sounding at 12:00 UTC on the following day (not shown), between $6.1-6.6 \mathrm{~km}$, with maximum ozone of about $90 \mathrm{ppb}$ at $6.4 \mathrm{~km}$ and the potential temperature increasing less sharply from $293 \mathrm{~K}$ to $297 \mathrm{~K}$ in this layer $\left(\mathrm{N} \approx 1.6 \cdot 10^{-2} \mathrm{~s}^{-1}\right)$. On 16 February the speed of the light wind was not greater than $8 \mathrm{~m} / \mathrm{s}$ throughout the troposphere, with a wind direction of $40-50^{\circ}$ below and above the layer and of $80-110^{\circ}$ within the layer. The wind increased slightly on 17 February, having a maximum speed as high as $15 \mathrm{~m} / \mathrm{s}$; this is, nevertheless, too low for a jet stream. Wind direction within the layer was about $130^{\circ}$ whereas outside the layer it was of $180-210^{\circ}$ below and about $100^{\circ}$ above the layer.

Such light winds observed at the station are in good agreement with the ECMWF wind and geopotential heights analysis (Fig. 3b). From this figure it is seen that the jet stream on the $300 \mathrm{hPa}$ surface was positioned far south of the station at 12:00 UTC on 16 February. Comparison of the ECMWF wind with radiosonde wind shows good agreement throughout troposphere and lower stratosphere, with a maximum absolute deviation of about $2 \mathrm{~m} / \mathrm{s}$. The train of upper-level lows can be seen on the map. The easternmost low was positioned above the archipelago of Novaya Zemlya. The second low is seen westward of the station, with its centre above the northwestern part of the Norwegian Sea. The most intensive third low is positioned southeast of Iceland within a developing trough.

The passage of the layer over the station is observed in the daily routine radio soundings performed at Sodankylä (Fig. 4). The tightening of the isotherms in the upper part of the picture shows the more stable stratosphere. Some tightening of the isotherms marking the stable layer can be seen in the centre of the picture between 6 and $8 \mathrm{~km}$. This layer appeared at noon on 15 February and had passed over the station by noon on 17 February. It can be seen that the 


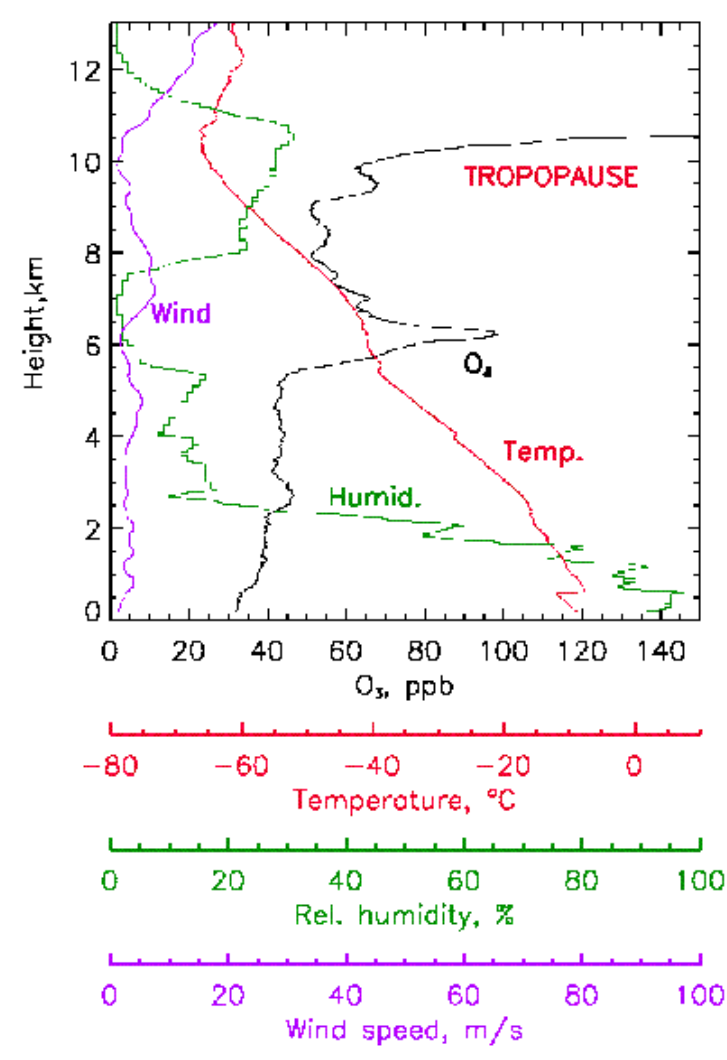

Fig. 3. Same as in Fig. 1 but at 12:00 UTC on 16 February 2000.

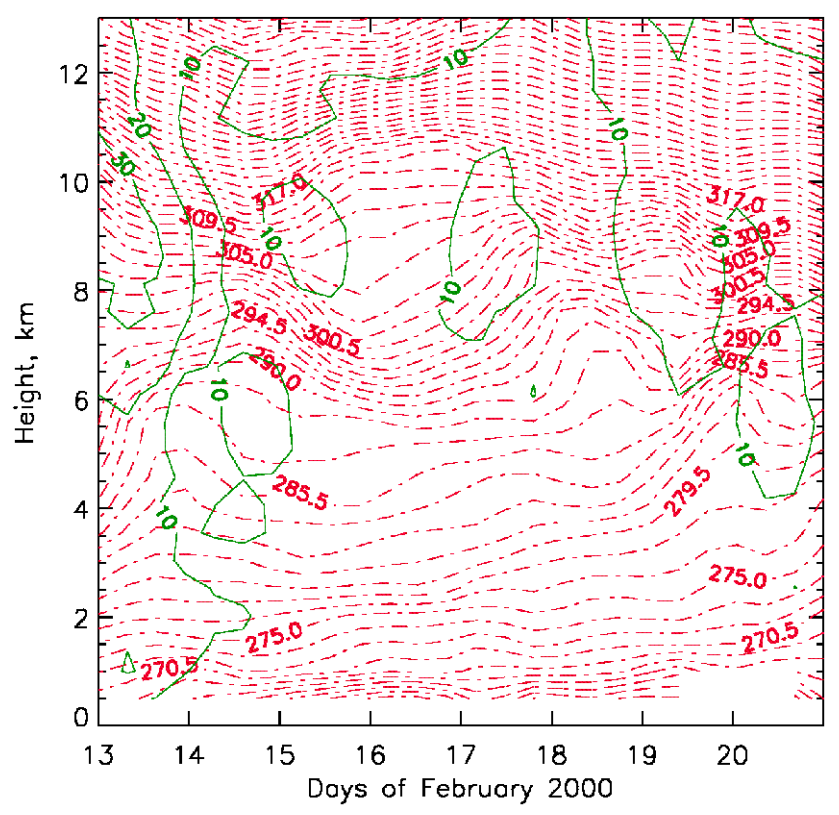

Fig. 4. Time series of potential temperature (red) and wind speed (green) at Sodankylä.

tropopause height before 15 February and after 17 February was positioned below $9 \mathrm{~km}$ at isentropic levels of about 295 K. During the passage of the layer on 15-17 Febru-

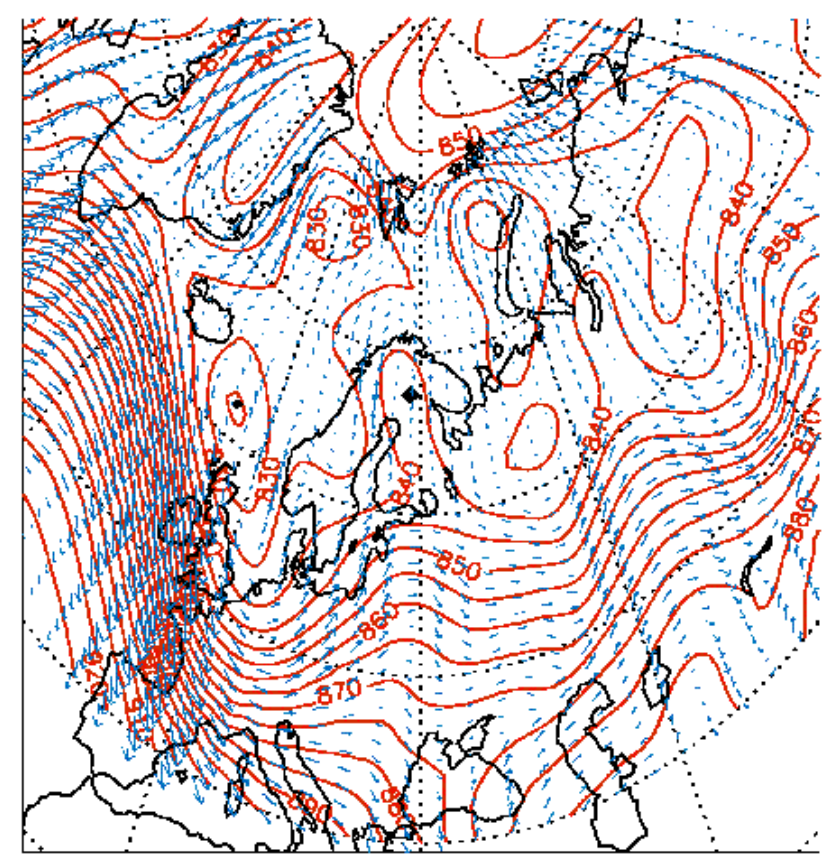

ary, the thermal tropopause above the station was located at altitudes of $10-11 \mathrm{~km}$, corresponding to isentropic levels of $317 \mathrm{~K}$. No jet stream had passed over the station since 13 February, and during the whole period, the tropospheric winds were less than $20 \mathrm{~m} / \mathrm{s}$. The bulb of less stable air between $7.5 \mathrm{~km}$ and $10.5 \mathrm{~km}$ on 15-17 February could be interpreted as a tropospheric intrusion into the lowermost stratosphere (Fig. 4). However, as can be seen from Fig. 3a, the inversion at $5.5 \mathrm{~km}$ does not satisfy the tropopause criteria and a well-defined thermal tropopause was positioned above $10 \mathrm{~km}$.

Figure 5 shows the ECMWF isentropic PV charts for the $295 \mathrm{~K}$ surface. An elongated band of high PV extended from Greenland towards Southern Scandinavia, indicating the position of the upper trough on 14 February (Fig. 5a). Development of the trough started on 11 February and reached its maximum magnitude by 14 February. The dynamical tropopause, defined as 1.6 PVU, descended to about the $700 \mathrm{hPa}$ pressure level, below the jet stream on the western flank of the trough. This descent was followed by tropopause fold formation. The surface cyclone and its associated cold front moved northeastward during 12-14 February, just ahead of the tropopause fold. On 15 February the surface cyclone began to decay over the southern part of the Barents Sea and the upper-level elongated band of high PVvalues became thinner and continued to stretch equatorwards (Fig. 5b). At 12:00 UTC, on 15 February, when the layer of 

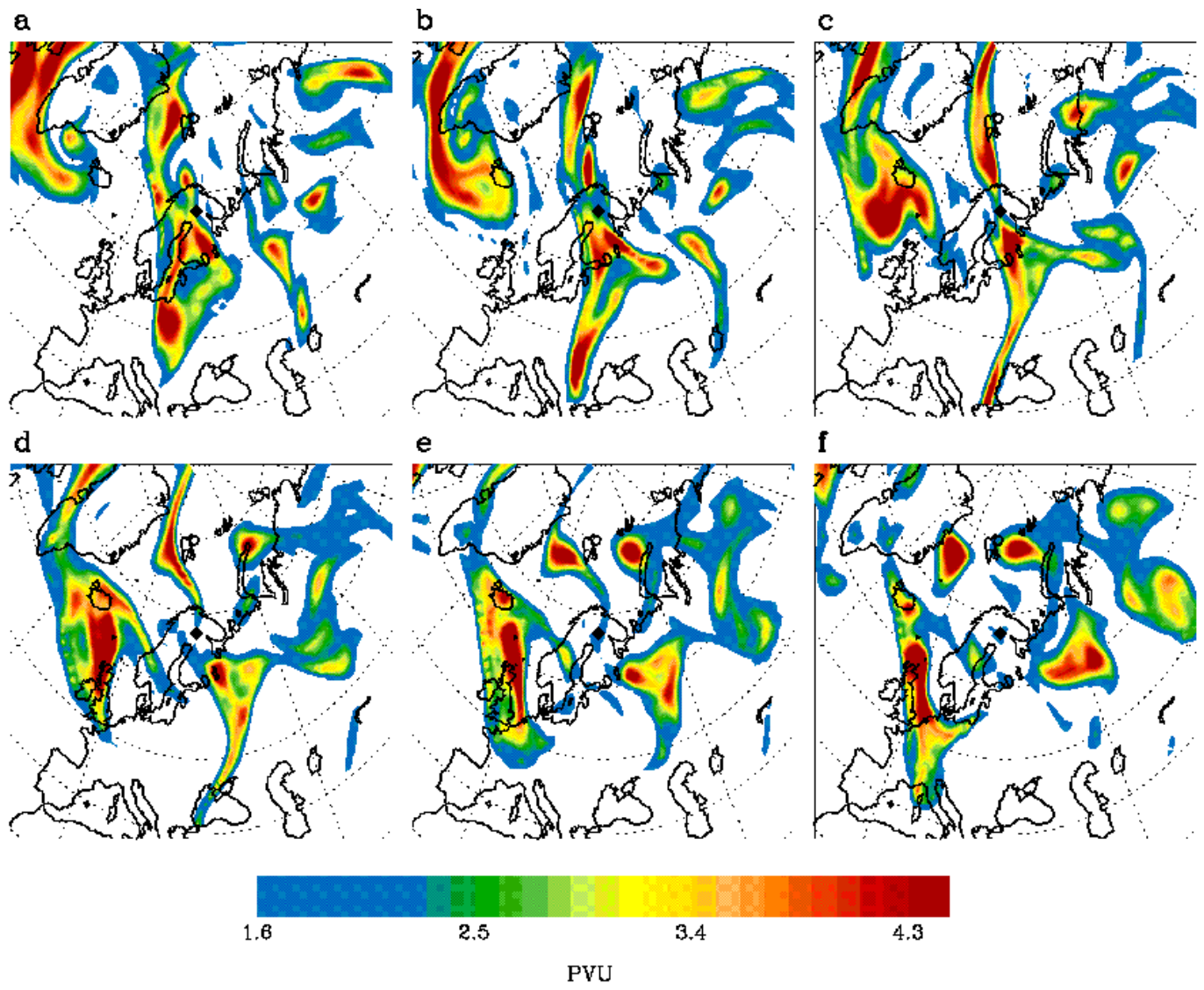

Fig. 5. PV charts calculated for the $295 \mathrm{~K}$ isentropic surface at (a) 12:00 UTC on 14 February; (b) 00:00 UTC (c) 12:00 UTC on 15 February (d) 00:00 UTC (e) 12:00 UTC on 16 February (f) 00:00 UTC on 17 February. Sodankylä is marked with a diamond. Only PV $>1.6 P$ VU is coloured.

stable air was first observed above Sodankylä, a thin belt of high PV connecting two bulbs of the initial PV area crossed Northern Finland right over the station (Fig. 5c). When the belt became broken, the streamer fragmented into two remnants, with a "finger" of high PV connected to the northern remnant being still positioned above the station (Fig. 5d-e). On 17 February this "finger" broke up into two spots, one being just above the station and another located above the southern Barents Sea (Fig. 4f). Subsequently, these spots disappeared from the ECMWF charts.

In order to investigate more thoroughly the origin of the ozone-rich layer observed above Sodankylä, a backward isentropic trajectory analysis was made (Fig. 6). To increase the robustness of the trajectory analyses, several trajectories were calculated covering the whole high PV region that appeared above Sodankylä. We used here the same technique as Gouget et al. (2000) for the investigation of the life-cycle of a mid-latitude cutoff low. Isentropic trajectories were calculated for $295 \mathrm{~K}$, corresponding to the height of the observed layer. The calculations were started at 12:00 UTC on 16 February. In total, more than 120 backward trajectories were calculated.

Figure 6a shows the trajectory endpoints at 00:00 UTC on 15 February, just before the streamer began to break up. The trajectories that started at 12: UTC on 16 February north of $73^{\circ} \mathrm{N}$ and west of $15^{\circ} \mathrm{E}$ (red points on maps) had PV values of more than 2 PVU (Fig. 6b). These trajectories correspond to an upper-level low which had developed by 16 February above the Norwegian Sea. It can be seen that, at 00:00 UTC on 15 February, they were clustered in the northwestern part of the trough (Fig. 6a). Trajectories that initialized east of $15^{\circ} \mathrm{E}$ (blue points on maps) possessed PV values of between 1.6 and 2 and correspond to the high PV "finger" (Fig. 6b). As seen from Figure 6a on the 15 February chart, they were grouped into an elongated band which curved from the northern part of Norway to the southern parts of the Barents Sea. This band intersects the boundary contour between the stratosphere and the troposphere, which means that trajectories have transferred from the tropopause region. Thus, it can be assumed that this "finger" is a region intermediate between the stratosphere and the troposphere.

Forward trajectories (Fig. 6c-f) were started from the same locations as the backward ones, to examine the fate of the air contained within the high PV region. Air parcels from the upper-level low remain more or less together, following the movement of the low above the southwestern part of the Barents Sea towards the Kola Peninsula. These trajectories remained in the stratosphere and moved with the low until 
a



c

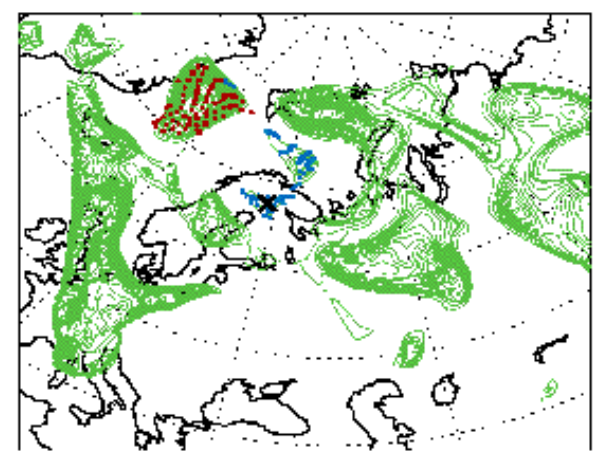

e

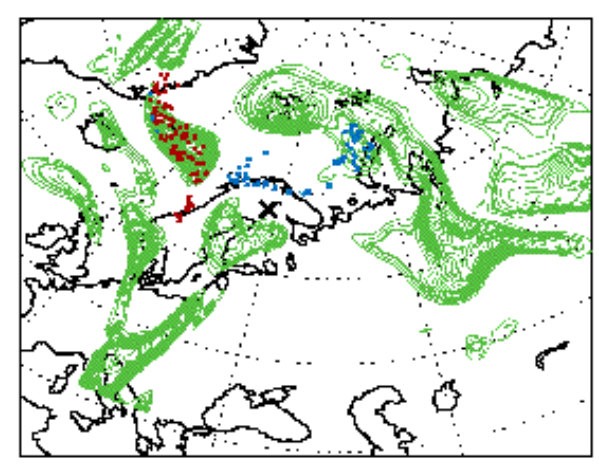

b
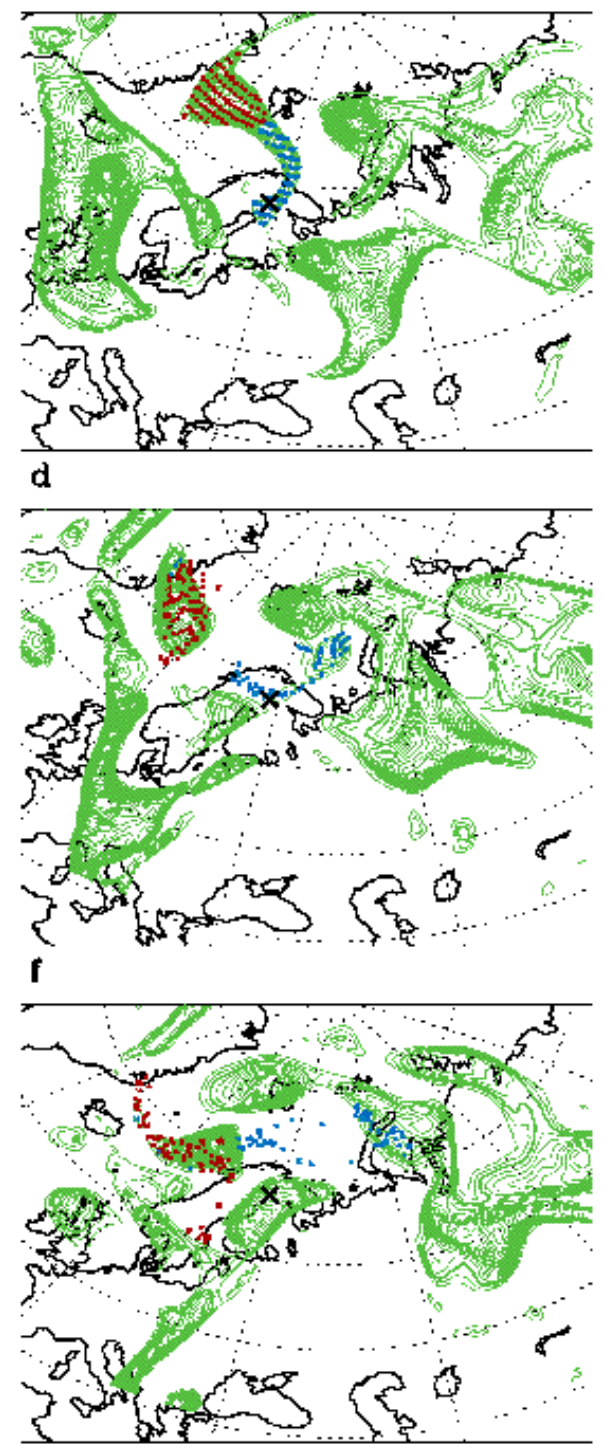

Fig. 6. Locations on the $295 \mathrm{~K}$ surface of (a) end-points of backward trajectories at 00:00 UTC on 15 February, (b) initial positions of trajectories at 12:00 UTC on 16 February; (c)-(f) end-points of forward trajectories at (c) 00:00 UTC (d) 12:00 UTC on 17 February; (e) 00:00 UTC (f) 12:00 UTC on 18 February. In each case the locations are superimposed on the corresponding PV chart. Only PV >1.6 PVU is coloured. Sodankylä is marked with a cross.

it became merged with a stationary trough above Siberia on 23 February. Trajectories started from the high PV "finger" separated into two groups (Fig. 6c) in the same way as the "finger" itself split into two parts (Fig. 5f). PV is a conservative tracer for the adiabatic motion, and isentropic trajectories should follow the PV distribution so long as the adiabatic restriction is valid. We believe that these small structures are real since they were resolved in both PV maps and trajectory analysis, which use different data sources. The northern group merged with another upper-level low positioned on 17 February above Spitsbergen (Fig. 6d). This group also probably remained within stratosphere and continued to move northwards within the extensive upper-level trough (Fig. 6ef). The second group, positioned on 17 February (Fig. 6c-d) above the station, is seen to diminish in PV to tropospheric values by 18 February (Fig. 6e). These trajectories travelled from the stratosphere to the troposphere and continued to move northwards outside the stratosphere (Fig. 6f).

The life-cycle of the high PV streamer described above differs from the example presented in Sect. 3. In this case the streamer did not propagate through the polar jet stream, and the fragmentation of the initial intrusion occurred on the poleward side of the jet. Another difference is that the evolution of the streamer, as well as the observation of the layer occurred on the $295 \mathrm{~K}$ isentropic surface, which is somewhat below the usual heights of mid-latitude stratospheretroposphere interactions. Nevertheless, there are still some similarities, such as wave-like deformation and the break-up 
of the streamer into separate vortices, which appear on synoptic charts as upper-level lows.

Consider now the isentropic level of $310 \mathrm{~K}$, which is higher than the height of the ozone-rich layer but below the thermal tropopause positioned over Sodankylä at the $317 \mathrm{~K}$ level. Figure 7a shows the PV distribution on the $310 \mathrm{~K}$ level for 12:00 UTC on 16 February. A wave-like "finger" of high PV is positioned east of the station, as well as east of the analogous "finger" at $295 \mathrm{~K}$. The most remarkable feature now is a thin, elongated tropospheric streamer stretching from the European part of Russia to Northern Scandinavia. The streamer tilted upstream and, in accordance with Peters and Waugh (1996), it corresponds to a P1 type of poleward Rossby wave breaking. A bulb of tropospheric air at the tip of the streamer is located just above the station. The line on Fig. 7a marks the direction of the cross section of PV (Fig. 7b). It can be seen that the tropospheric air is located above the stratospheric intrusion. The PV distribution above the station is in good agreement with the ozone vertical profile presented in Fig. 3a. High PV values are found in the ozone-rich layer on the $295 \mathrm{~K}$ level, while the low PV layer above the stratospheric intrusion corresponds to tropospheric values of ozone.

As in the example in Sect. 3, we conclude that the generation of layering in this case resulted from shear-induced differential horizontal advection. Air from the ozone-rich layer at the $295 \mathrm{~K}$ level was advected from the Arctic stratosphere, while air within the ozone minimum at the $310 \mathrm{~K}$ level originated from the mid-latitude troposphere. The tropospheric origin of the air at $310 \mathrm{~K}$ level is confirmed by both the PV chart and the cross section in Fig. 7a and b. However, in this case it was a mid-latitude tropospheric streamer that propagated north of the jet stream in the region of the weak zonal flow. Therefore, it is therefore convenient to classify this case as a generation of layering from the poleward breaking of a Rossby wave. Propagation of the tropospheric streamer resulted in a rising of the tropopause in the region limited by streamer boundaries. Horizontal ozone gradients at the streamer boundaries in combination with differential vertical shear caused folding of ozone surfaces that was observed in the vertical soundings as a laminated structure.

\section{Another example of poleward rossby wave breaking}

We will now present another example of upper troposphere layering resulting from poleward Rossby wave breaking. This case was observed at the Ny-Ålesund station on 27 November 1994. Ozone-rich, dry and stable air was observed on the 12:00 UTC sounding at $5 \mathrm{~km}$ (Fig. 8a), corresponding to about the $300 \mathrm{~K}$ isentropic level. A temperature inversion was observed throughout the lower part of the ozone layer; the relative humidity dropped within the inversion from $70 \%$ at its bottom to lower than $20 \%$ at its top. The minimum in relative humidity was located higher than the ozone maximum. Another peculiarity of this example is that the relative humidity reached values of more than $60 \%$ at about $6.5 \mathrm{~km}$, above the stratospheric layer.

In this case the station is located at the edge of the polar vortex, north of the tropospheric jet stream (Fig. 8b). A large trough located over Russia southeastward of Spitsbergen is the most dominant synoptic-scale feature in the figure. This developed during previous days as the result of an equatorward jet stream excursion. Poleward advection of tropospheric air at the $310 \mathrm{~K}$ level can be seen in Fig. 9a as a band of low PV values west of the trough just above the station. This tropospheric streamer tilted upstream and its tip began to roll up above eastern Greenland. Upstream tilting and thinning of tropospheric streamers are characteristics of a P1 poleward Rossby wave-breaking scenario. A cross section of PV through the streamer (Fig. 9b) shows a layer of high PV tilted from the stratosphere into the troposphere. The PV maximum above the station is positioned at about $300 \mathrm{~K}$, which is in good agreement with the ozone sounding measurements. As in the case in Sect. 4, propagation of the tropospheric streamer poleward through the jet stream lifted the tropopause higher than $310 \mathrm{~K}$ level. Outside the boundaries of the streamer, the Arctic tropopause was positioned at about $302 \mathrm{~K}$ and $295 \mathrm{~K}$ south and north of the streamer, respectively.

\section{Statistics of layering observation in troposphere}

We now consider the statistics of layers of stratospheric origin in the upper and middle troposphere obtained from Sodankylä and Ny-Ålesund data sets over the period 19892000. We used the criteria for stability, ozone and humidity described in Sect. 2, in order to pick out all the cases when stratospheric layers were observed in the troposphere. All the tropopause fold cases with high wind speeds and vertical wind shear were rejected from the final statistics. The fraction of the fold events at the stations was found to be about 6\% at Sodankylä and about 5\% in Ny-Ålesund. The remaining cases were regarded as layers of stratospheric air in the troposphere resulting from the shear-induced differential horizontal advection or, shortly, filaments. It turned out that only 15 cases (2\% of all observations) for Sodankylä and 26 cases (3\%) for $\mathrm{Ny}$-Ålesund, including the examples presented in the previous sections, fulfilled the criteria. Analysis of the synoptic situations, as well as the isentropic PV charts for the cases showed that only a minor fraction of them could be attributed to equatorward Rossby wave breaking. At the more southern station of Sodankylä, layers were observed equatorward of the jet stream in 3 cases (20\% of all layering events at Sodankylä), including the case presented above. Stratospheric streamers analogous to that presented in the case study in Sect. 3 were found in the vicinity of the station in all these events. Such filaments were never observed at Ny-Ålesund. This can probably be explained by the geographical location of the station, so far north of the usual position of the tropospheric jet stream. A large caseto-case variability in the synoptic situations was observed for 

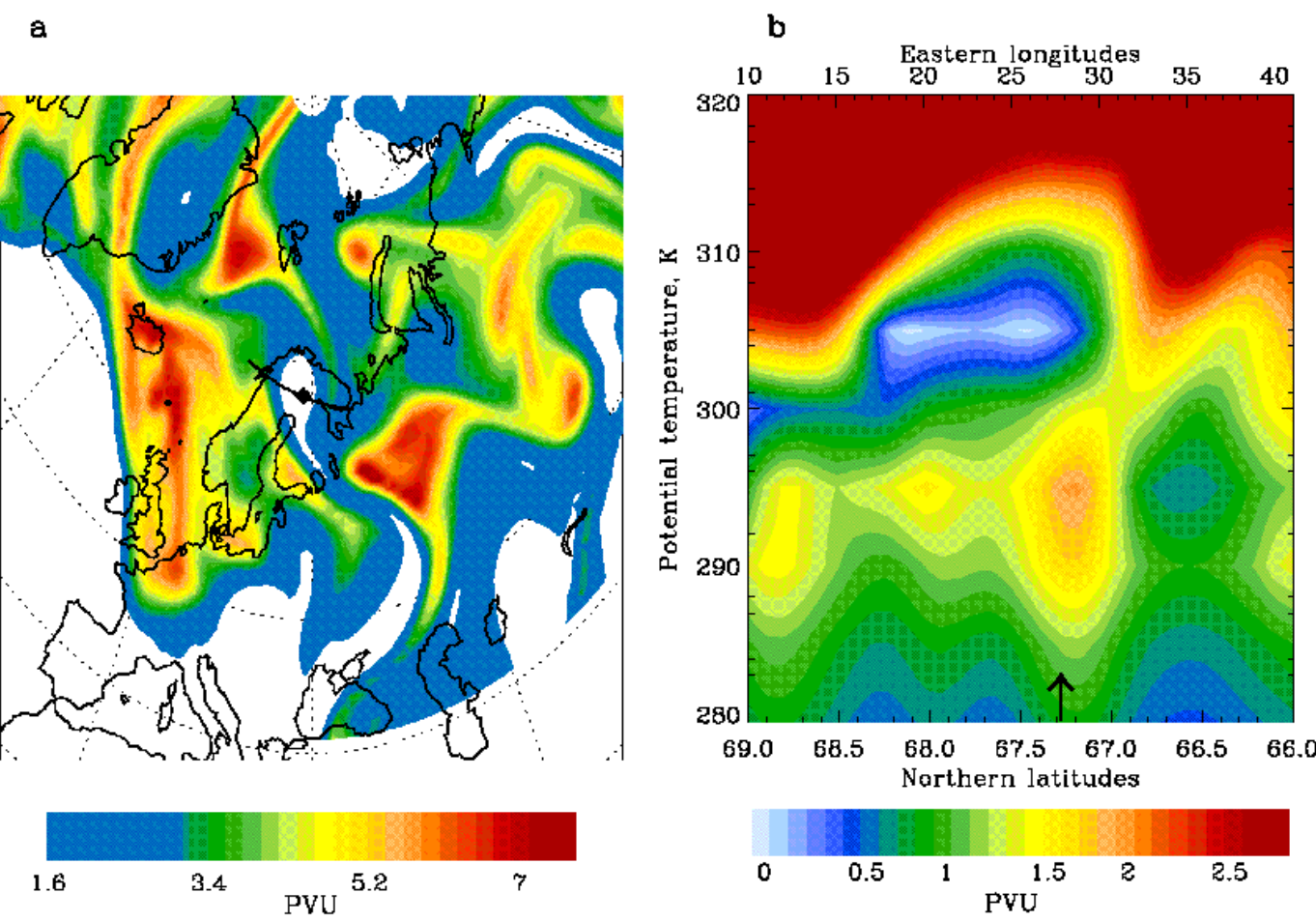

Fig. 7. (a) PV chart for $310 \mathrm{~K}$ at 12:00 UTC on 16 February. Sodankylä is marked with a diamond. Only PV $>1.6 \mathrm{PVU}$ is coloured (b) Cross section of PV along the black line from (a) across the tropospheric filament. The station is marked with an arrow.


Fig. 8. Same as in Fig. 1 but at Ny-Ålesund at 12:00 UTC on 27 November 1994. 
the second group of stratospheric laminae that were detected north of the jet stream. Nevertheless, in about half of all the cases, streamers of tropospheric air were found in the vicinity of the stations on isentropic surfaces just above the stratospheric layers detected.

As was suggested in the Introduction and shown in the case studies, tropopause fold development usually precedes the generation of filaments. This implies that the frequency of filament observations should be of the same magnitude as that of tropopause fold occurrence. Comparison of the fraction of the filaments with the fraction of the folds shows that the first one is about 2-3 times less. On a global scale, tropopause fold occurrences were derived from meteorological analysis by seeking a combined maximum of Q-vector divergence and PV in the upper troposphere (Beekmann et al., 1997). It was found that some 20-30 folds per year occur in the Northern Scandinavia and Barents Sea region (see Beekmann et al., 1997, Fig. 2). In order to convert the number of folds into a fraction of time, it was assumed that the time scale of a fold is about 1 day. This yields a fraction of folds of $5-8 \%$, which is comparable to the fold statistic obtained in the present paper. Again, it is seen that the filament fraction is about 2-4 times less than the fold fraction.

It should be kept in mind that the criteria used in our investigation were developed for tropopause fold detection. Stratospheric air injected within a tropopause fold into the troposphere interacts with tropospheric air for a shorter time than the aged layers investigated here. Adjustment of the algorithm to detect long-lived filaments probably would have resulted in the detection of only most intense cases. A different frequency of the filaments would be obtained if we were to take into account the fact that, during the advection following the initialization of the intrusion, the air parcels could have lost some of their stratospheric characteristics through diabatic processes. Forster et al. (2000) investigated the decay of an idealized stratospheric filament within the troposphere due to radiative processes. They found that, over a period of 10 days, a pure PV anomaly with a horizontal scale much larger than its vertical scale decays through radiation to some $25 \%$ of its initial strength. It was also found that, if dryness of the stratospheric filament is taken into consideration, the PV anomaly decays after 10 days to some $40 \%$ of its initial strength. For the events investigated in our case studies, the period between the initiation and the observation of the layers varies between 2 and 4 days. Taking into account the model results of Forster et al. (2000) and assuming an exponential rate of decay, we find that a static stability anomaly, that is part of a PV anomaly decays to some $70 \%$ of its initial strength after 3 days. Assuming then that an ozone and humidity anomaly would decay at the same rate, we relaxed our criteria for stability, ozone and humidity by $30 \%$ each.

These modifications in the criteria resulted in an increase in the fraction of filaments to $6 \%$ for Sodankylä and to $7 \%$ for Ny-Ålesund. This value shows quite good agreement with the previously mentioned tropopause fold frequency. Since layers observed at Ny-Alesund are associated with the poleward wave breaking, they should be connected with the tropopause folds which occurred south of the station. The maximum of tropopause fold occurrence is observed in the latitude band $40-70^{\circ}$ (Beekman et al., 1997) and it probably explains some exceeding of the filament over fold fraction at the station.

Statistical results presented above depend on criteria used for their derivation and so should be taken with some care. For example, relaxing criteria for stability, ozone and humidity by $50 \%$ each would result in an increase in the fraction of filaments to $8 \%$ for Sodankylä and to $9 \%$ for Ny-Ålesund, whereas relaxing by only $10 \%$ would result in a fraction of about 3\% for both stations. More important is to stress that, according to our results, laminae in the mid- and upper troposphere are common in the Arctic. Their occurrence is not confined to the Arctic jet streams which were earlier investigated by Shapiro et al. (1987). Rather, they are ubiquitous elsewhere because of quasi-horizontal transport due to the breaking of Rossby waves. Quasi-horizontal transport of the laminae in low latitudes far away from the jet stream was observed also by Zachariasse et al. (2000), who revealed signs of stratospheric intrusions into the deep tropics in more than one-third of the ozone profiles.

\section{Conclusions}

Stratospheric laminae in the troposphere are of great interest in stratosphere-troposphere exchange. This paper presents, to our knowledge, first detailed case studies and statistics of stratospheric layers observed in the Arctic troposphere. Since layering near the Arctic jet stream associated with vertical tilting of the stratospheric air in the tropopause fold has been studied before (Shapiro et al., 1987), we concentrated here on the layers resulted from horizontal transport away from the jet stream, which we refer to as filaments. The ozonesonde data bases for two stations in the European sector of the Arctic were used to investigate the generation of filaments in the upper and middle troposphere. It is known that shear-induced differential advection can cause tracer surfaces to stretch, leading to quasi-horizontal laminae-like tracer structures (see Appenzeller and Holton, 1997, Fig. 1). The formation of both stratospheric and tropospheric streamers and their propagation that can be seen on isentropic PV charts, represent an example of shear-induced differential advection. Stratospheric streamers that propagate through the polar jet stream into the upper troposphere are a common feature of mid-latitude weather system development (Appenzeller et al., 1996). It was shown in this paper that advection of these streamers can generate laminae-like structures in ozone, as well as in static stability profiles. The Arctic stations examined in this paper are usually located to the north of the polar jet stream. Nevertheless, it was found that during poleward excursions of the jet stream, stratospheric streamers generated near the jet can be observed at these Arctic stations south of the jet stream, although they only account for a small fraction of observed layering events. In a dynamical context the formation of stratospheric stream- 
a
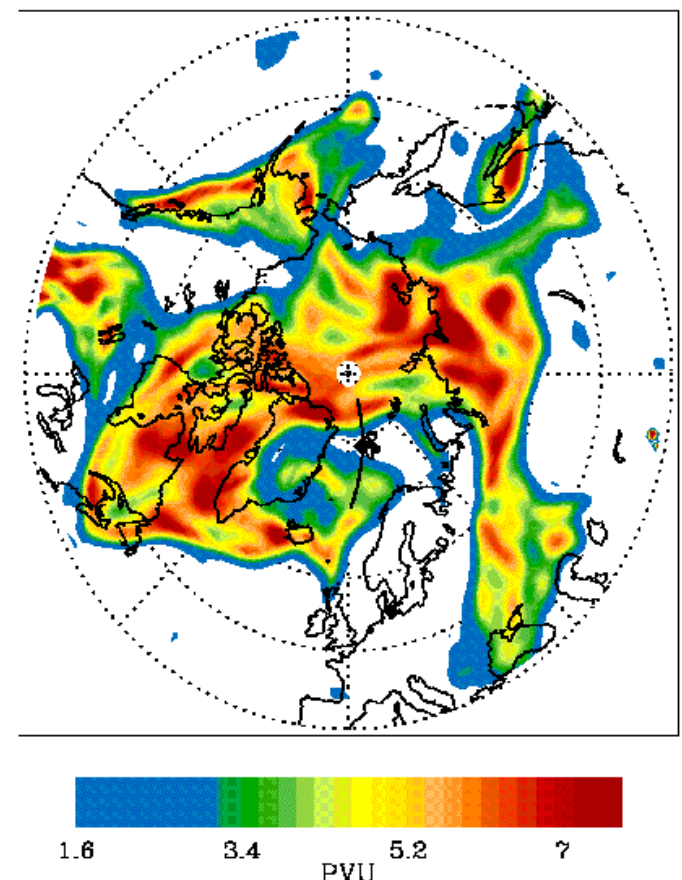

b

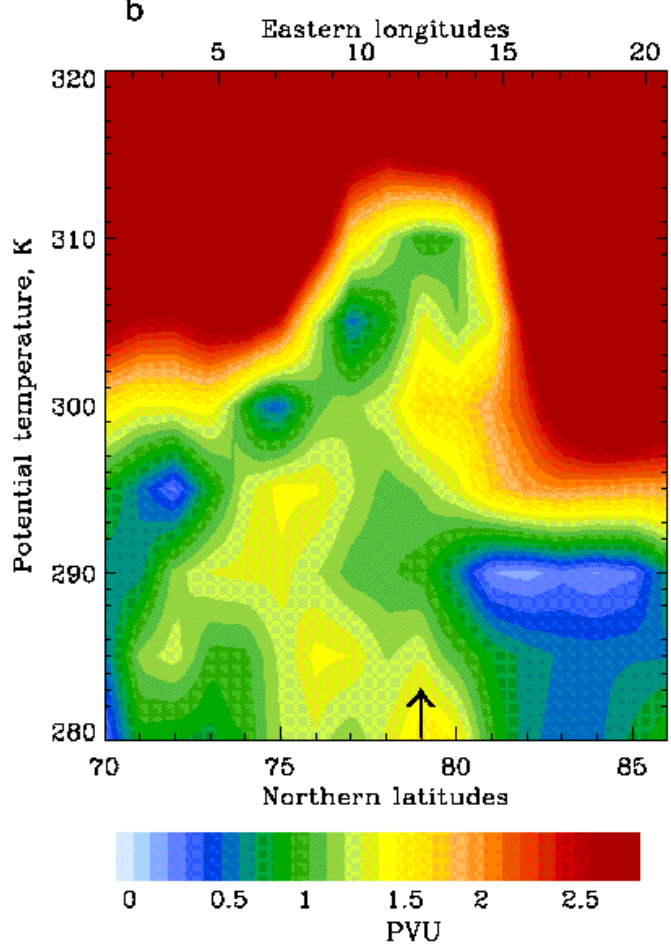

Fig. 9. (a) PV chart for $310 \mathrm{~K}$ at 12:00 UTC on 27 November 1994. Ny-Ålesund is marked with a diamond. Only PV>1.6 PVU is coloured (b) Cross section of PV along the black line from (a) across the tropospheric filament. The station is marked with an arrow.

ers can be referred to as equatorward Rossby-wave breaking. In the same manner, formation of tropospheric streamers that propagate through the jet stream poleward is known as poleward Rossby-wave breaking. It was found by Bradshaw et al. (2002), that the vertical gradients in background wind fields that govern the growth in the Rossby wave amplitude can lead to the generation of layers in the lower stratosphere poleward of the subtropical jet stream. The mechanisms causing laminae formation in the upper troposphere north of the polar jet stream examined in this paper are, in principle, the same. However, we found that the propagation of the tropospheric streamers investigated here can cause the tropopause to rise in the region limited by the streamer boundaries. This produces gradients of ozone on isentropic surfaces intersecting the tropopause. Differential vertical shear at the streamer boundaries converts horizontal ozone gradient into vertical ozone gradient, which is observed in the vertical soundings as a laminated structure. Differential advection was evident from the observation of a significant shift of wind direction through the filaments in all investigated cases and it enhances initial layering which could develop during the subsidence of the air in the tropopause fold. In general, according to our investigation, formation of the filaments looks as follows: subsidence of the air in the tropopause fold during upper-level front development; streamer formation and propagation with subsequent horizontal stretching of the ozone surfaces and lamination at the streamer boundaries during Rossby-wave breaking.

The importance of the streamers as STE agents was dis- cussed in detail by Appenzeller et al. (1996). Break up of the streamer into separate vortices on the isentropic surface points to the irreversibility of the process. Horizontal stretching and lamination, studied in the present paper, substantially enhance the potential for the mixing due to an increase in the surface area of the intrusion. Some indications of the irreversible mixing were obtained here from the trajectory analysis. A statistical study revealed that layering due to poleward Rossby wave breaking accounts for at least half of the all layering events detected in this survey. In general, assuming a lifetime of the filaments of 3 days, we found signs of stratospheric intrusions away from the jet stream in about 6$7 \%$ of all soundings at both stations in the period 1989-2000. These estimations suffer, in some extent, from uncertainties in the quantitative definition of filaments. It is possible, for example, that filaments older than 3 days were not included in these statistics. Nevertheless, we believe that layering in the upper troposphere generated by Rossby-wave breaking represents an important mechanism in the stratospheretroposphere exchange in the Arctic.

Acknowledgements. We wish to thank H.Aulamo for helping in the ECMWF data retrieval. The ECMWF is acknowledged for providing meteorological analysis data. We would like to thank the NOAA Air Resources Laboratory for the on-line trajectory calculation service.

Topical Editor O. Boucher thanks two referees for their help in evaluating this paper. 


\section{References}

Ancellet, G., Pelon, J., Beekmann, M., and Papagiannis, A.: Ground based lidar studies of ozone exchanges between the stratosphere and the troposphere, J. Geophys. Res., 96, 22 40122 421, 1991.

Ancellet, G., Beekmann, M., and Papagiannis, A.: Impact of a cutoff low development on downward transport of ozone in the troposphere, J. Geophys. Res., 99, 3451-3468, 1994.

Appenzeller, C. and Davies, H. C.: Structure of stratospheric intrusions into the troposphere, Nature, 358, 570-572, 1992.

Appenzeller, C. and Holton, J. R.: Tracer lamination in the stratosphere: A global climatology, J. Geophys. Res., 102, $13555-$ $13569,1997$.

Appenzeller, C., Davies, H. C., and Norton, W. A.: Fragmentation of stratospheric intrusions, J. Geophys. Res., 101, 1435-1456, 1996.

Beekmann, M., Ancellet, G., Blonsky, S., De Muer, D., Ebel, A., Elbern, H., Hendricks, J., Kowol, J., Mancier, C., Sladkovic, R., Smit, H. G. J., Speth, P., Trickl, T., and Van Haver, Ph.: Regional and global tropopause fold occurrence and related ozone flux across the tropopause, J. Atmos. Chem., 28, 29-44, 1997.

Bithell, M., Vaughan, G., and Gray L. J.: Persistence of stratospheric ozone layers in the troposphere, Atmos. Environment, 34, 2563-2570, 2000

Bradshaw, N., Vaughan, G., and Ancellet, G.: Generation of layering in the lower stratosphere by a breaking Rossby wave, J. Geophys. Res., 107(D2), 4011, doi: 10.1029/2001JD000432, 2002.

Browell, E. V., Danielsen, E., Ismail, S., Gregory, G. L., and Beck, S. M.: Tropopause fold structure determined from airborne lidar and in situ measurement J. Geophys. Res., 92, 2112-2120, 1987.

Cho, J. U. N., Newell, R. E., Bui, T. P., Browell, E. V., Fenn, M. A., Mahoney, M. J., Gregory, G. L., Sachse, G. W., Vay, S. A., Kuscera, T. L., and Thompson, A. M.: Observations of convective and dynamical instabilities in tropopause folds and their contribution to stratosphere-troposphere exchange, J. Geophys. Res., 104, 21 549-21 569, 1999.

Danielsen, E. and Hipskind, R. S.: Stratospheric-tropospheric exchange at polar latitudes in summer, J. Geophys. Res., 85, 393400, 1980

Danielsen, E. and Monhen, V.: Project Dustorm Report: Ozone transport, in situ measurements, and meteorological analysis of tropopause folding, J. Geophys. Res., 82, 5867-5877, 1977.

Danielsen, E. F., Bleck, R., Shedlovsky, J., Wartburg, A., Haagenson, P., and Pollok, W.: Observed distribution of radioactivity, ozone, and potential vorticity associated with tropopause folding, J. Geophys. Res., 75, 2353-2361, 1970.

Danielsen, E., Hipskind, R. S., Gaines, S., Sachse, G., Gregory, G. L., and Hill, G. F.: Three-dimensional analysis of potential vorticity associated with tropopause folds and observed variations of ozone and carbon monoxide, J. Geophys. Res., 92, 2103-2111, 1987.

Dobson, G. M. B.: The laminated structure of the ozone in the atmosphere, Q .J. R. Meteorol. Soc., 99, 599-607, 1973.

Draxler, R. R.: Boundary layer isentropic and kinematic trajectories duing the August 1993 North Atlantic Regional Experiment Intensive, J. Geophys. Res., 101, 29 255-29 268, 1996.
Esler, J. G., Tan, D. G. H., Haynes, P. H, Evans, M. J, Law, K. S., Plantevin, P.-H., and Pyle, J. A.: Stratosphere-troposphere exchange: Chemical sensitivity to mixing, J. Geophys. Res., 106, 4717-4731, 2001.

Foster, C. and Wirth, V.: Radiative decay of idealized stratospheric filaments in the troposphere, J. Geophys. Res., 105, 10169 $10184,2000$.

Gouget, H., Vaughan, G., Marenco, A., and Smit, H. G. J.: Decay of a cut-off low and contribution to stratosphere-troposphere exchange, Q.J.R. Meteorol. Soc., 126, 1117-1141, 2000.

Holton, J. R., Haynes, P. H., McIntyre, M. E., Douglass, A. E., Rood, R. B., and Pfister, L.: Stratosphere-troposphere exchange, Rev. Geophys., 33, 403-439, 1995.

Hoskins, B. J. and Bretherton, F. P.: Atmospheric frontogenesis models: Mathematical formulation and solution, J. Atmos. Sci., 29, 11-37, 1972.

Langford, A. O. and Reid, S. J.: Dissipation and mixing of a smallscale stratospheric intrusion in the upper troposphere, J. Geophys. Res., 103, 31 265-31 276, 1998.

Langford, A. O., Masters, C. D., Proffitt, M. H., Hsie, E.-Y., and Tuck, A. F.: Ozone measurements in a tropopause fold associated with cut-off low system, Geophys. Res. Lett., 23, 2501-2504, 1996.

Miloshevich, L. M., Vömel, H., Paukkunen, A., Heymsfield, A. J., and Oltmans S. J.: Characterization and Correction of Relative Humidity Measurements from Vaisala RS80-A Radiosondes at Cold Temperatures, J. Atmos. Ocean. Technology, 18, 135-156, 2001.

McIntyre, M. E. and Palmer, T. N.: Breaking planetary waves in the stratosphere, Nature, 305, 593-600, 1983.

Peters, D. and Waugh, D. W.: Influence of barotropic shear on the poleward advection of upper-tropospheric air, J. Atmos. Sci., 53 , 3031-3013, 1996.

Price, J. D. and Vaughan, G.: Statistical studies of cut-off low systems, Ann. Geophysicae, 10, 96-102, 1992.

Rummukainen, M., Knudsen, B., and von der Gathen, P.: Dynamical diagnostics of the edges of the polar vortices, Ann. Geophysicae, 12, 1114-1118, 1994.

Schär C. and Davies H. C.: An instability of mature cold front, J. Atmos. Sci., 47, 929-950, 1990.

Shapiro, M. A.: Turbulent mixing within tropopause folds as a mechanism for the exchange of chemical constituents between the stratosphere and the troposphere, J. Atmos. Sci., 37, 994 1004, 1980.

Shapiro, M. A., Hampel, T., and Krueger, A. J.: The Arctic tropopause fold, Mon. Wea. Rev., 115, 444-454, 1986.

Thorncroft, C. D., Hoskins, B. J., and McIntyre, M. E.: Two paradigms of baroclinic-wave life-cycle behavior, Q. J. R. Meteorol. Soc., 119, 17-55, 1993.

Van Haver, P., Beekmann, M., De Muer, D., and Mancier, C.: Climatology of tropopause folds at midlatitudes, Geophys. Res. Lett., 23, 1033-1036, 1996.

Zachariasse, M., van Velthoven, P. F. J., Smit, H. G. J., Lelieveld, J., Mandal, T. K., and Kelder, H.: Influence of stratospheretroposphere exchange on tropospheric ozone over the tropical Indian Ocean during the winter monsoon, J. Geophys. Res., 105, 15 403-15 416, 2000. 